\title{
Utilização Energética da Glicerina Residual do Processo de Fabricação do Biodiesel
}

por David M. M. Pinho

Data de publicação na Web: 15 de fevereiro de 2013 Recebido em 4 de novembro de 2012 Aceito para publicação 10 de fevereiro de 2013

autorização para uso de biodiesel no mercado brasileiro ocorreu em 2005, quando a produção e comercialização foram de alguns poucos milhões de litros, e se tornou obrigatório em 2008. Desde que se tornou obrigatório, a produção de biodiesel apresentou um crescimento vertiginoso. De fato, em 2008 foram produzidos pela indústria oleoquímica brasileira aproximadamente 1 bilhão de litros de biodiesel e em 2011 já se alcançou a produção de 2.431.128.000 litros, sendo usado como matéria-prima óleo de soja $(82,3 \%)$, sebo (12,9\%), algodão $(2,4 \%)$, além de outras oleaginosas $(2,2 \%){ }^{1}$ Essa produção de biodiesel gera como coproduto mais de 243.000.000 litros de glicerina. No entanto, o mercado de consumo da glicerina é tradicionalmente na fabricação de cosméticos e na indústria farmacêutica, que não possuem elasticidade para absorver essa produção. ${ }^{2}$ Assim, um desafio atual da indústria é encontrar alternativas de mercado para a glicerina, até mesmo para tornar sustentável a cadeia de produção de biodiesel.

Uma forma alternativa de uso deste coproduto foi desenvolvida pela Cerâmica Tijolos Trevo, situada em Nova Alvorada do Sul-MS, que utiliza a glicerina gerada na produção de biodiesel da usina de Biotins, em Paraíso do Tocantins-TO, como combustível em fornos para a fabricação de artefatos cerâmicos. Primeiro o forno é aquecido até $500^{\circ} \mathrm{C}$ utilizando palha de arroz, por este ser produzido em grandes quantidades no estado e por conter pouca umidade, e, em seguida, é adicionada a glicerina. Desta forma se evita a geração de gases nocivos gerados durante a queima incompleta do glicerol, como a acroleína (prop-2-en-1-al) que é cancerígena, mas que se decompõe acima de $300^{\circ} \mathrm{C}$, evitando assim sua emissão para a atmosfera. ${ }^{3}$ Com isso a empresa conseguiu substituir a lenha e ainda ganha créditos de carbono. Antes de ser usada, a glicerina deve passar por uma etapa de purificação, que é feita na indústria química Ouro Negro em Campo Grande-MS. ${ }^{4}$ Ao trocar a lenha pela glicerina a empresa aumentou os custos operacionais, que, entretanto, retornam com a venda de créditos de carbono.

Este é um interessante exemplo de arranjo local, onde o passivo ambiental de uma empresa resulta na solução energética de uma segunda. 0 biodiesel somente se estabelecerá de vez no mercado quando a glicerina tiver valor econômico. A solução para este problema pode ser simples, como a sua queima em caldeiras.

\section{Agradecimentos}

0 autor agradece às diferentes agências que financiam as pesquisas do Grupo de Pesquisas Rede de Estudos em Oleoquímica (CNPq, FINEP, FAPEAL, FAPDF), ao INCT-CATÁLISE e em especial à CAPES 
(PROCAD 2005, Projeto no 0023051; e PROCAD NF 2009, Projeto no 735/2010) que permitiram a mobilidade de alunos e professores das equipes. $O$ autor agradece também ao CNPq e CAPES pelas bolsas de pesquisa concedidas aos pesquisadores e alunos de graduação e pós-graduação.
Referências bibliográficas

${ }^{1}$ Sítio da Agência Nacional do Petróleo, Gás Natural e Biocombustíveis (ANP).

Disponível em:

<www.anp.gov.br>.

Acessado em: 22 junho 2012.

${ }^{2}$ Sítio do Biodeieselbr.com.

Disponível em:

$<$ http://www.biodieselbr.co $\mathrm{m} /$ biodiesel/glicerina/biodies el-glicerina.htm>. Acessado em: 15 fevereiro 2013.

${ }^{3}$ Sítio Sustainable Carbon

Disponível em:

$<$ http://carbonosustentavelb rasil.wordpress.com/2010/07 29/uso-de-glicerina-porceramica-e-destaque-emrevista/>. Acessado em: 15 fevereiro 2013.

${ }^{4}$ Sítio da Associação Nacional da Indústria Cerâmica (ANICER). Disponível em: <http://www.anicer.com.br/i ndex.asp?pg=institucional di reita. $a s p \&$ secao $=10 \& i d=130$ \& revista $=2 W A 004509087 \mathrm{EW}$ RTXLZ873BDG28>. Acessado em: 15 fevereiro 2013.

Universidade de Brasília, Laboratório de Materiais e Combustíveis, Instituto de Química, CP 4478, CEP: 70904-970, Brasília-DF, Brasil.

M david mark2003@hotmail.com

DOI: 10.5935/1984-6835.20130013 